\title{
RISK BASED INTERNAL AUDIT: PERSEPCTIVES OFFERED TO CORPORATIONS AND BANKS
}

\author{
Tatiana Danescu ${ }^{l}$ \\ Anca Oltean (Muntean) ${ }^{2}$ \\ Raluca Sandru ${ }^{3}$
}

\begin{abstract}
Internal audit aims at providing an independent opinion about whether the objectives of one institution are achieved, and if not to define the circumstance that hinder from accomplishing them. In the context of value addition to the organization, there is increasing pressure for addressing exposure to risks, regulatory requirements for risk assessment and quantification play in these sense a great role. The shift from a traditional approach on internal audit is required by current trends of corporate governance and risk management. In this paper we propose a procedural guidance framework on how to address problems regarding operational risk internal auditing by stressing particularities of banking organization working on Romanian territory. Our conclusions draw attention to the fact that acknowledging the regulation efforts undertaken by supervision authority for efficient risk management, a risk based internal audit can be implemented having in mind the advantages that this form of audit involves.
\end{abstract}

Key words: Based Internal Audit, Internal Controls, Risk Assessment, Risk Management,

JEL codes: G32

\section{Introduction}

The requirements of the Romanian and international business market, characterized by a continuous change, lead economic entities to a strategy conception that has a great importance to their survival in the market.

Related to the actual financial crisis and to the fact that the problems of the financial international system are determinate by a wrong risk management, the internal audit function became very important for every economic entity.

The introduction in Romania is relative recent, representing the general effort of the management for a better control of company's activity, in the public sector and in the private sector.

The starting point in regulation of the internal audit in Romanian was the Government Ordinance no. 119/31.08.1999 republished referring to internal audit and preventing financial control, publicized in the Official Monitor no. 430/31.08.1999 and the law 672/2002 that settle the internal audit for public institutions. Only in 2004 we can discuss about a law frame for internal audit for economic entities. Private institutions have possibilities and in the same time they are obligate to realize the internal audit activity in conformity with Internal Audit Standards issued by Romanian Financial Auditors Room (CAFR).

The internal audit field knows a big development in the world among the multinational companies, yet in Romania this field is recently created and it's based on old structures of the

\footnotetext{
1 PhD Univ. Prof., Faculty of Economics, Juridical and Administrative Sciences, "Petru Maior" University, 1 Nicolae Iorga Street, 540088, Tg. Mures, Romania, tatiana_danescu@yahoo.com

2 PhD Candidate, Faculty of Economics, Juridical and Administrative Sciences, "Petru Maior" University, 1 Nicolae Iorga Street, 540088, Tg. Mures, Romania, oltean_anca2005@yahoo.com

3 PhD Candidate, Faculty of Economics, Juridical and Administrative Sciences, , "Petru Maior" University, 1 Nicolae Iorga Street, 540088, Tg. Mures, Romania, avram_co@yahoo.com
} 
financial audit and doesn't know a wide development. The autochthon entities use in elaboration of the audit planes the strategy of the internal audit known today as being "traditional internal audit".

Along with these models the risk based internal audit (RBIA) had being promoted by the big international audit firm since 90's. This new model of audit allows the auditor to make comments and advices for the entity's management regarding business risks and the implications of those risks, providing an added-value client service.

Even if the internal audit field is recently new in Romania, the new concept of business risk management is gaining space in preoccupations of the internal auditors and the management of economic entities.

So that, we find legitimacy of the audit that is based on risks even Performance Standard, IIA 2010, and in its Application Standard, IIA 2010.A. We find there the fact that the internal audit chief department must elaborate an audit plan based on risks to establish the audit activities priorities according to the economic entity's objectives.

RBIA orientation to the future's risks is the main difference between this new model of audit and the traditional one that looks backwards, presenting to the entity's management only the past risks. RBIA improves the economic entity's activities providing the maximum of efficiency. From this point of view, the internal auditor is now a "partner" not a "bad controller" and the entity's management turns in to the client of internal audit.

So, regarding this, we offer the words of D. Griffits as the definition of internal audit:"internal audit offer to the economic entities an independent and objective opinion regarding the risks that the entities face, telling if they are kept at a lower level possible by the internal control" (Griffits, 2006).

As we may see, this definition outlines the tight link between "risk" and "audit".

\section{Literature review: Specific risks that must be accounted in corporations and in the banking industry}

Sometimes referred to as company risk, a business risk can be the result of internal conditions, as well as some external factors that may be evident in the wider business community.

The risk may appear because of many factor, such as: the absence of the working capital, the absence of a managerial strategy, the lack of the financial knowledge, low level of investments, etc. (Danescu, 2003).

A business risk is a circumstance or a factor that may have a negative impact on the operation or profitability of a given company. That means that these factors are "circumstances and events that put into danger the achievement of the entity's objectives" (Camelia Liliana Dobroteanu, Laurentiu Dobroteanu, 2007).

In context that the entities are dealing with activities that involve the many kind of risks, the companies, in order to stand up against the great competition on the market, should search to obtain an assurance that the risks are being reduced to the lower level possible.

When it comes to outside factors that can create an element of business risk, one of the most predominant risks is that of a change in demand for the goods and services produced by the company. If the change is a positive one, and the demand for the offerings of the company increase, the amount of risk is decreased a great deal. However, if consumer demands for the offerings decreases, either due to loss of business to competitors or a change in general economic condition, the amount of risk involved to investors will increase significantly. When a company's risk factor is considered to be increased due to outside factors that are beyond the control of the company to correct, chances of attracting new investors is severely limited (www.wsegeek.com).

Internal factors may also result in the development of significant business risk for the investor. Often, these are factors that can be identified and corrected. If flagging sales can be attributed to an ineffectual marketing effort or a sales force that is not performing up to expectations, making changes in the marketing approach or restructuring the sales effort will often 
result in minimizing the perception of business risk on the part of potential investors. The same is true if a company's manufacturing facilities are not operating at optimum efficiency. Revamping the operational structure of the plants and facilities will decrease the element of business risk and result in higher profits at the same level of production and sales, which will in turn make the company more attractive to potential investors (www.wsegeek).

In the particular case of banking institutions, the quality of banking assets is highly correlated with the management of specific risks that characterize banking activities. The starting point for this matter is the Basel II Accord which statuates the role of banking entities in identifing, assessing, monitoring and controlling the risks that can generate loss from the lending activity, form market fluctuation and from operating activities. .

Following the view of the Committee, credit risk is most simply defined as the potential that a bank borrower or counterparty will fail to meet its obligations in accordance with agreed terms. The goal of credit risk management is to maximise a bank's risk-adjusted rate of return by maintaining credit risk exposure within acceptable parameters. The effective management of credit risk is a critical component of a comprehensive approach to risk management and essential to the long-term success of any banking organisation (BIS, 1999).

Market risk is defined as the risk of losses in on and off-balance-sheet positions arising from movements in market prices.

The risks subject to this requirement are:

- The risks pertaining to interest rate related instruments and equities in the trading book;

- Foreign exchange risk and commodities risk throughout the bank.

The capital charges for foreign exchange risk and for commodities risk will apply to banks' total currency and commodity positions, subject to some discretion to exclude structural foreign exchange positions.

In close connection with credit risk and market risk, operational risk refers to direct or indirect financial losses resulting from inadequate or failed internal processes, people and systems, or from external events.

The problem of addressing operational risks is of special interest for audit since they ingrain a strong internal component. In this sense such risks are specific to the factors and circumstances of each banking institution including: banking specific processes, culture, personnel, technology and have a strong dynamic in time changing along with business strategy, processes, technology and competition.The Basel Committee on Banking and Supervision defined operational risk (BIS, 2001) as the risk of loss resulting from inadequate or failed internal procedures, people, systems or from external events. Extending this somewhat ambiguous definition a detailed loss event type classification was presented (BIS, 2004) which contains: internal fraud, external fraud, employment practices and workspace safety, clients products and business practices, damage to physical assets, business disruption and system failures, execution delivery and process management.

\section{Starting points for a procedural guidance on auditing operational risk in Romanian banking sector}

In practical terms, the issue of managing operational risks is viewed under the Basel II framework corroborated with the Principles for enhancing corporate governemnt in banks proposed by the Basel Committee in March 2010. The Capital Adequacy Framework initiated in 2001 aims at providing a robust risk management view that rests on three pillars: the first pillar addresses the problem of well capitalized banks in the context of defining capital charges for specific risks: credit, market and operational, the second pillar refers to regulatory validation and supervision, the third pillar encourages reliable financial disclosure in order to achieve market discipline.

As Chorafas (2004) points out, the common ground of the three pillars is the credit institution's own internal control system. Open feedback channels and objective information reaching all levels of management are essential characteristics that support the notions that give 
essence to the three pillars framework. Moreover, because operational risks represent loss resulting from inadequate or failed internal processes and from external events, all three of the pillars encompass operational risks.

Lessons learned from the American and European banking experience showed that managing these risks generates all sorts of challenges. Explanation is given on the one hand from the inaccurate perception about the nature of this risks and lack of appropriate understanding by senior management, on the other hand scarcity of resources, little regulatory guidance on specific key issues, few proven methodologies and tools are to be blamed (KPMG, 2008)

Regarding the Romanian banking system, the National Bank of Romania (NBR) prefigured a four step implementation strategy of Basel II principles, the actual application started with the year 2008. Connecting with the European Capital Requirements Directives the NBR emitted the 18/2009 Regulation which articulates the importance given to the development of internal evaluation of capital requirements to risks. The timescale for total compliance is 30 June 2010. A great deal of significance is put on issues like: creating sound internal control systems, defining methodologies of risks assessment and quantification, providing independent, objective opinion about effectiveness of risk management and internal controls including regulatory compliance by the bank, advancing solid explanations in case of differences between results obtained by applying intern methodology vs. NBR requirements.

The most recent statistics provided by the NBR considering this subject are dated 30.09.2009 (Georgescu, 2009). The structure of Romanian banking system is as follows - total bank assets 76,8 billion EURO, which represents $65 \%$ of GBP derived from:

- Banks with majority domestic capital - 6 institutions

- Banks with majority foreign capital - 36 institutions

- Foreign bank branches 10

From the total of 42 banking institution, only 32 report the capital requirements to the NBR, the foreign bank branches having no obligation in this sense.

Concerning operational risk 93,55\% of reporting banking institution have chosen the basic indicator approach whereas the rest of $6,45 \%$ adopted the standardized approach. None of the reporting institutions adopted the advanced measurement approach. Moreover, regarding the structure of required capital, $11 \%$ is assessed from operational risks, $88 \%$ represents capital required in order to manage credit risk and $1 \%$ is allocated for managing market risk.

The data evidence indicates poor capacities concerning future development of internal ratings-based methods considering the fact that only two credit institutions adopted an approach that is to be developed into a more sophisticated and risk sensitive tool for required capital sizing.

Indeed these IRB methods come with a price but as Chorafas (2003) pinpoints some credit institutions think of cutting corners in operational risk control studies, but others aptly suggest that in the longer run this will be counterproductive. Skipping the discovery and experimental phase, for example, will prove to be very costly later on. From another point of view capital allocation must not only account for identified major areas of risk but also reflect on business perspectives.

Taking this context we must consider the function that is played by internal audit in supporting the achievement of objectives by evaluating and commenting on the effectiveness of risk assessment, internal control systems and corporate government processes.

\section{Methodology}

The methodological approach of operational risks considered in the light of Basel II agreement has been focused on investigating the methods of identifying the type of risks specific especially to banks but also to other financial entities.

The authors put in the center of their attention the review and synthesis of the overall reference frame of the topic in specialty literature, international regulations, specific national legislation and professional standards in the concerned field. 
The initial requirement was to study the identification of the types of risks, starting from the domestic inspection system standing for the finding out and preventing processes developed by an entity with an aim at mitigating the frequency and severity of operational risks. That is because the domestic inspection system operates by a reduction in the risk exposure generated by the business environment, by detection of the causes, prevention of specific risks from occurring and by a diminution of effects of such risks the very moment that certain events take place.

In order to highlight the risks specific to financial activity they had to monitor within the present investigation the specific processes of domestic control (acknowledgement of a transaction, minute verification before employing people) but also the general ones (control of risks and processes of self-assessment used to find out and evaluate the risks) at several banks of Romania

Also at the center of their concerns was the study of internal audit risk based activities, a model of audit grounded by means of reporting about the manner risks are managed from the perspective of the future and versus the objectives of: identification of risks, giving priority of audit areas, allocation of resources for audit depending on to the risk assessment.

Based on the review on the Set of Rules 18/2009 highlighting a conceptual frame of the risk management that has been a support in the run of investigation carried out, together with the considerations identified and approached in the national and international specialty literature, we have approached the premises required for the development of an internal audit focused on risks, while placing at the center of attention the fact that risk is a measure of probability and of the magnitude that some unfavorable events actually occur, or to be more specific, risk is the due measure of the impact that operational risk has in an organization.

\section{Three steps for practical implementation}

\section{STEP 1: Assessing risk maturity}

The bank risk maturity is taken as the starting point. Scoring and sorting risk with the aim of creating a database - a risk register - is the first step to take into consideration. The assessment of risk appetite concerning operational risks is provided by management and from the evaluation of this register the internal auditor can conclude the risk maturity of the bank. The risk register will provide information needed for creation of the audit plan.

Following the IIA U.K and Ireland Positions (Institute of Internal Auditors, 2003) organization risk maturity can take the contour of:

Risk enabled: Risk management and internal controls are fully embedded into the operations. Risk management and monitoring controls are sophisticated, a complete risk register is provided. The emphasize of the audit work regards proper processes development.

Risk managed: Enterprise wide approach to risk management are developed and communicated, nevertheless weaknesses are found and are to be reedited.

Risk defined: Risk appetite defined. Strategies and policies are in place and communicated. Internal audit will act as a consultant to facilitate the construction of a complete risk register. Individual audit must emphasize on understanding risk maturity in the area being audited, great importance is put on identification of risk, also consultancy may be needed where weaknesses are found.

Risk aware: no risk register is available, only few managers will have determined their risk. Internal audit will act as a consultant to undertake risk assessment, and to determine the work required to implement a risk framework.

Risk naïve: Internal audit will promote or will provide consultation on establishing a risk management framework.

STEP 2: Developing a general strategy of internal audit and the audit plan

The risk and audit universe is an extension of the management's risk register. This will consist of: risks identified by management and scores attached to them; processes and objectives that this risks threaten; identification of the "owner" of the risk- the person responsible with risk 
management; the audit that provides an opinion about the management of each risk, details of the last and next audits, details of controls and managing the risk.

An important step is the allocation of risk to audits which will determine the scope of individual audit. Audit is allocated by category of risk identified and by the response of the organization to risk. Possible responses given by the organization to risk can be:

- to tolerate- if there is no possibility of cost efficient risk reduction: in this case the need of contingency plan should be considered;

- to transfer- outsourcing most of the cost of impact;

- to terminate- remove circumstance giving rise to risk;

- to treat- implement a system of internal control that can reduce risk below risk appetite.

After achieving an image about risks, scores, audit linked to them, the approach that is used should be considered. The audit can either provide assurance or it can offer consultancy. Assurance will be adopted if control score is high - confirming that risks are properly managed. The consultancy approach is recommended if control scores are low, audit will facilitate management's identification, assessment, managing and monitoring of operational risk.

Before publishing the audit plan, resource allocation is necessary, it is required to estimate a total number of days per audit and also human resources are to be assigned.

The planning phase can be divided into following:

1. divide banking operations into operational risk auditable entities/activities (e.g. divisions, branches, risk related projects, activities);

2. identification of key risk factors: (e.g. failed transactions, errors and omissions, fluctuation of personnel, activity growth, fraud cases detected, product development and new operation, adequacy of security measures, major changes in operations, programs, systems and control, deviations from approved budget, etc.) that are to be expressed quantitatively, qualitatively or in combination;

3. assignment of a risk rating to each auditable entity/activity (e.g. high/medium/low);

4. decision about which audit to perform considering risk domains and management request.

\section{STEP 3: The individual assurance audit}

In this step the principle of guidance is that for each risk covered, the audit should give reasonable assurance that (Griffiths, 2006):

- management has identified, assessed and responded to risks above the risk appetite;

- internal controls are effective in reducing the inherent risks to below the risk appetite;

- reduction of residual risks within the risk appetite, or the board has been informed that they will be tolerated, transferred or terminated;

- monitoring processes by management to ensure they continue to operate effectively;

- Following the types of risk maturity emphasize on auditing should be:

- for risk managed and risk enabled - management processes e.g. resources, documentation, methods and reporting;

- for risk defined - risk identification, are controls operating?

- risk naïve and risk aware - management involvement in risk assignment.

\section{Conclusions}

Looking at the most recent statistics Romanian banking system operates with a rough measurement of operational risk, since it is not based on any loss data specific to the institution. Advancing from the standardized approach to the internal measurements method will provide greater accuracy by ensuring sensitivity to measurements. But in order to achieve that, internal risk based methods are to be developed. We proposed a procedural guidance about how RBIA could be 
developed in the purpose of adding value to the bank activity supporting the NBR view in creating efficient risk management.

Two of the most important factors to be taken into consideration about the current state are:

1. Considering gross income as a proxy indicator for operational risk presents at least a major inconvenient that is to be stated: the more money one entity makes the more it is taxed in terms of operational risk capital reserves even if the level of operational risk profiling the business is low. In this sense this op. risk measurement is better fitted for small, unsophisticated banks. An advanced method will select more indicators providing accurate operational risk description.

2. Regulations provided by the supervisor authority reflect a high tendency regarding the implementation of a risk management framework. Having this as one of the most favorable premises, RBIA presents some of the following advantages: management has to face up to their responsibility to risk and to become more involved, resources are justified by the proportion of risks that are to be audited, efficiency is assured by directing audits to high risk area whereas financial area may not always represent great risks, recommendation are to be used in risk mitigation resulting surplus value. RBIA involves the whole organization, it is less introspective by contributing to objective performance.

\section{References}

1. Chorafas, Dimitris, 2004. Economic Capital Allocation with Basel I. Elsevier Publishers.

2. Chorafas Dimitris, 2003. Operational Risk with Basel II. Elsevier Publishers.

3. Danescu, Tatiana, 2003. Leading the affairs. Dacia Publishing House.

4. Dobroteanu, Camelia Liliana, Dobroteanu, Laurentiu, 2007. Internal audit. Infomega Publishing House.

5. Georgescu Florin, 2009. Romanian banking system - present and perspectives. Presentation at Finmedia Conferences, 1066.

6. Griffiths, David, M., 2006. Risk Based Internal Audit - Three Views of Implementation, available at www.internalaudit.biz

7. Griffits, David, 2006. Introduction to risk based internal audit. ICSA Publishing House.

8. Sharma, G. V., 2005. Risk Based Internal Audit in Banks. Chartered Accountant, pp. 1057.

9. Basel Committee on Banking Supervision, 2001. Operational Risk Supporting Document for the New Basel II Approach, available at http://www.bis.org/publ/bcbsca07.pdf

10. Basel Committee on Banking Supervision, 2004. International Convergence of Capital Measurement and Capital Standards A Revised Framework, Annex, available at www.theiia.org/download.cfm?file $=54908$

11. The Institute of Internal Auditors, 2003. Risk Based Internal Auditing, Position Statement, available at http://www.bis.org/publ/bcbs128.pdf

12. KPMG Report, 2008, available at http://us.kpmg.com/microsite/attachments/2008/Managing_Operational_Risk.pdf

13. National Bank of Romania, 2009. Regulation 18, available at: http://www.bnro.ro/apage. aspx ?pid=404\&actId=322828

14. www.wsegeek.com 